\title{
Review
}

Journal of Innate

Immunity
J Innate Immun 2010;2:238-247

DOI: $\underline{10.1159 / 000296508}$
Received: December 14, 2009

Accepted after revision: February 10, 2010

Published online: March 16, 2010

\section{Dual Role of Heat Shock Proteins as Regulators of Apoptosis and Innate Immunity}

\author{
Anne-Laure Joly Guillaume Wettstein Gregoire Mignot François Ghiringhelli \\ Carmen Garrido
}

INSERM U866, Faculty of Medicine and Pharmacy, University of Dijon, Dijon, France

\section{Key Words}

Apoptosis $\cdot$ Cell fate $\cdot$ Programmed cell death $\cdot$ Heat shock protein $70 \cdot$ Heat shock protein 90

\begin{abstract}
Stress or heat shock proteins (HSPs) 70 and 90 are powerful chaperones whose expression is induced in response to a wide variety of physiological and environmental insults. These proteins have different functions depending on their intracellular or extracellular location. Intracellular HSPs have a protective function. They allow the cells to survive potentially lethal conditions. The cytoprotective functions of HSPs can largely be explained by their anti-apoptotic properties. HSP70 and HSP90 can directly interact with different proteins of the tightly regulated programmed cell death machinery and thereby block the apoptotic process at distinct key points. In cancer cells, where the expression of HSP70 and/or HSP90 is frequently abnormally high, they participate in oncogenesis and in resistance to chemotherapy. Therefore, the inhibition of HSPs has become an interesting strategy in cancer therapy. In contrast to intracellular HSPs, extracellularly located or membrane-bound HSPs mediate immunological functions. They can elicit an immune response providing a link between innate and adaptive immune sys-
\end{abstract}

tems. In cancer, most immunotherapeutical approaches based on extracellular HSPs exploit their carrier function for immunogenic peptides. This review will focus on the roles of HSP70 and HSP90 in apoptosis and in innate immunity and how these functions are being exploited in cancer therapy.

Copyright $\odot 2010$ S. Karger AG, Basel

\section{Introduction}

Heat shock proteins (HSPs) were first discovered in Drosophila in 1962 as a set of proteins that accumulates in the cells after a heat shock and has thermoresistance proprieties. Latter studies demonstrated that HSPs are expressed in all living organisms and are the most conserved proteins present both in prokaryotes and eukaryotes. HSPs are now also more generally known as stress proteins because they are induced in response to a wide variety of physiological and environmental insults. HSPs have a cytoprotective function and act as molecular chaperones by assisting the folding of nascent or misfolded proteins and by preventing their aggregation. Mammalian HSPs have been classified into 5 families according to their molecular weight: HSP110, HSP90, HSP70, HSP60 and the family of small HSPs. Each family is composed of

\section{KARGER}

Fax +4161306 1234

E-Mail karger@karger.ch

www.karger.com
(C) 2010 S. Karger AG, Basel

$1662-811 X / 10 / 0023-0238 \$ 26.00 / 0$

Accessible online at:

www.karger.com/jin
Dr. Carmen Garrido

INSERM U866, Faculty of Medicine and Pharmacy, University of Dijon

7, Boulevard Jeanne d'Arc

FR-21000 Dijon (France)

Tel. +33 38039 3284, Fax +33 38039 3434, E-Mail cgarrido@u-bourgogne.fr 
members expressed constitutively or regulated inductively and which are targeted to different subcellular compartments.

Among the different HSPs, the ATP-dependent chaperone families HSP70 and HSP90 are the most studied by their involvement in cancer. The most studied members of the HSP70 family are inducible HSP70 (also called HSP72 or HSPA1) and the constitutive HSC70 (HSP73 or HSPA8). HSP70 is hardly expressed at the basal level in non-stressed 'normal' (non-transformed) cells, but its expression is strongly and transitorily induced after many different stresses, including oxidative stress or anticancer chemotherapy, thus allowing the cell to survive under lethal conditions. In cancer cells, the expression of HSP70 is abnormally high, and may participate in oncogenesis and in resistance to chemotherapy by interfering with apoptosis signaling.

The HSP90 protein family includes HSP $90 \alpha$ (now also called HSPC1), HSP90ß (HSPC3) and gp96 (HSPC4). The two HSP90 isoforms are very abundant cytosolic proteins representing more than $1 \%$ of total proteins, and this expression can be further stimulated by certain stresses. gp96 is an endoplasmic reticulum (ER) member and constitutes the main secreted chaperone. HSP90 can also accumulate in cancer cells and has been shown to contribute to tumorigenicity and cancer cell resistance both by its role in apoptosis and by its chaperone function stabilizing many kinases involved in cancer cell signaling.

HSP70 and HSP90, although mainly cytosolic/nuclear proteins, can also have an extracellular location. Several mechanisms may account for the release of these HSPs, including necrosis. HSPs could then act on the immune system alone or via their bound peptides. This review deals with the dual function of these HSPs: the intracellular anti-apoptotic function and the extracellular immunogenic function. In both cases, the interest of targeting HSPs in cancer therapy is discussed.

\section{Intracellular Roles of HSP70 and HSP90: Balancing Apoptosis and Cell Survival}

\section{HSPs as Cytoprotective Proteins}

HSP70

The HSP70 family constitutes the most conserved and best-studied class of HSPs. Under normal conditions, HSP70 participates in the folding of newly synthesized polypeptides, the assembly of multi-protein complexes and the transport of proteins across cellular membranes.
HSP70 is also a powerful anti-apoptotic protein that can act at different key points, both upstream and downstream of the mitochondria, affecting both the extrinsic and intrinsic pathways of apoptosis (fig. 1).

At a pre-mitochondrial level, HSP70 can interact with the death receptor signaling pathway. In Bcr-Abl expressing cells, HSP70 is able to bind to death receptors DR4 and DR5, thus inhibiting the TRAIL-induced assembly of the death-inducing signaling complex (DISC) [1]. Exposure of hematopoietic cells to TNF induces the activity of the pro-apoptotic double-stranded RNA-dependent protein kinase (PKR). Together with its co-chaperone HSP40, HSP70 via its ATPase domain is able to stabilize the Fanconi anemia complementation group C (FANCC), an inhibitor of PKR, resulting in TNF-induced apoptosis inhibition [2].

HSP70 has also been shown to stabilize survival kinases by phosphorylation modifications. HSP70 can bind to protein kinase $\mathrm{C}$ via the kinase's unphosphorylated $\mathrm{C}$ terminus, therefore priming the kinase for rephosphorylation and stabilizing the protein. In a similar manner, HSP70 binds Akt, a kinase that generates a survival signal, resulting in its stabilization [3]. After TNF-induced DISC formation and caspase 8 activation, HSP70 can inhibit BID activation and downstream events [4]. HSP70 has been shown to block BAX translocation, thus preventing mitochondrial outer membrane permeabilization. More recently, HSP70 has been demonstrated to interact with another Bcl-2 family member, Mcl-1. This anti-apoptotic protein is degraded upon heat stress, leading to BAX activation. Under these conditions, over-expression of HSP70 allows the stabilization of Mcl-1, thus preventing mitochondrial events [5]. In NIH 3T3 cells exposed to UV, over-expressed HSP70 interacts with stressactivated kinases such as the pro-apoptotic c-Jun $\mathrm{N}$-terminal kinase (JNK), leading to its inhibition [6]. Overexpression of HSP70 also inhibited $\mathrm{H}_{2} \mathrm{O}_{2}$-induced activation of apoptosis signal-regulating kinase 1 as well as that of downstream kinases in the p38 mitogen-activated protein kinase signaling cascade [7]. However, in an acidic environment, heat-induced HSP70 failed to suppress JNK activation and other apoptotic events such as BAX translocation and caspase-3 activation [8]. In apoptosis induced by hyperosmolarity, HSP70 has been found to modulate JNK and extracellular-regulated signal kinase (ERK) phosphorylations, leading to the inhibition of BAD pro-apoptotic activity [9].

Downstream of mitochondria permeabilization, HSP70, via its ATPase domain, is able to interact with apoptosis protease-activating factor-1 (APAF-1), thereby 


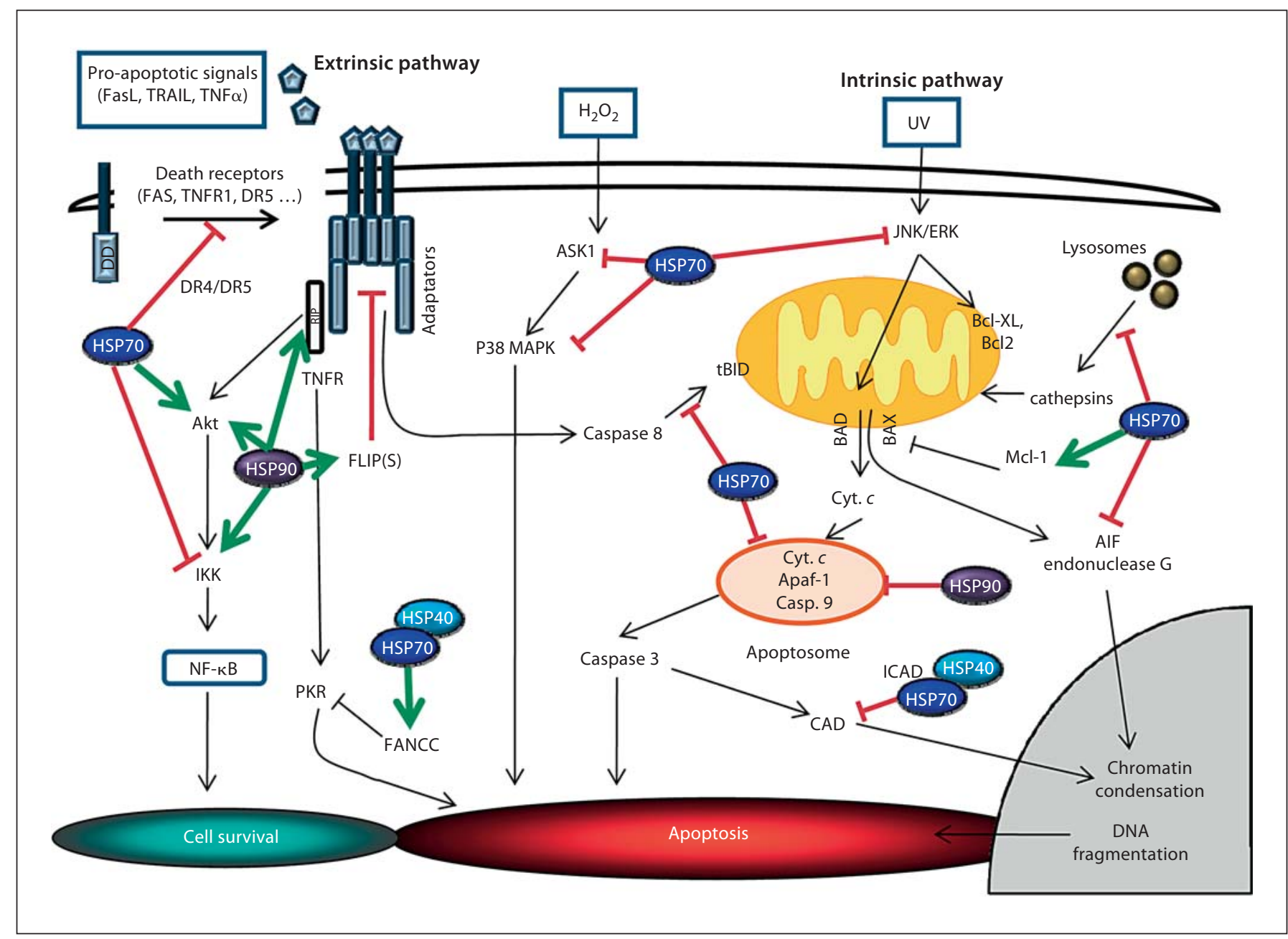

Fig. 1. Schematic representation of HSP70 and HSP90 regulatory functions in the intrinsic and extrinsic pathways to death. HSPs can block the mitochondrial intrinsic pathway of apoptosis by interacting with key proteins at 3 levels: (1) upstream of the mitochondria, thereby modulating signaling pathways (HSP70 modulates the activation of stress-activated kinases such as Akt, JNK or ERK); (2) at the mitochondrial level, controlling the release of cy- tochrome $c$ by interaction with BAX for instance; and (3) at the post-mitochondrial level, by blocking apoptosis by their interaction with APAF-1. HSPs can also block the extrinsic pathway at different levels. They can interact with the death receptors (DR4 and DR5), they can inhibit Bid cleavage and thus the activation of the mitochondria pathway and they can neutralize AIF and inhibit cathepsines. inhibiting recruitment of procaspase-9 to the apoptosome and the consequent caspase-3 activation [10]. The inhibitor of CAD, ICAD, is essential for generating properly folded CAD. When ICAD, is cleaved, CAD is released and enters the nucleus to degrade the chromosomal DNA. The enzymatic activity and proper folding of CAD has been reported to be regulated by HSP70, its co-chaperone HSP40 and ICAD [11].

HSP can also have important anti-apoptotic functions downstream of caspase activation. For example, HSP70 can protect caspase- 3 targets from proteolysis. Our team has demonstrated that during erythroid differentiation, HSP70 protects the transcription factor GATA-1 from caspase-3 cleavage, thus inhibiting erythroblast apoptosis [12].

HSP70 can also prevent caspase-independent apoptosis pathways. Our group has observed that over-expression of HSP70 protects Apaf- $1^{-/-}$cells from apoptotic cell death induced by serum withdrawal. Indeed, HSP70 directly binds to apoptosis-inducing factor (AIF) and inhibits AIF-induced chromatin condensation [13]. 
Finally, in stress conditions, HSP70 inhibits cathepsins release by stabilizing lysosome membranes. This can lead to autophagic cell death inhibition in some cell models [14] and in others, due to a cross-talk between lysosomes and mitochondria, to an inhibition of mitochondrial permeabilization and apoptosis [15]. Recently, Jaattela's group demonstrated the interaction of HSP70 with lysosome membranes. Following stress, HSP70 is able to bind the endolysosomal anionic phospholipid bis(monoacylglycero)phosphate, an important co-factor for the activity of acid shingomyelinase leading to lysosome membrane stabilization and normal lysosome storage functions [16].

In conclusion, HSP70 is a decisive negative regulator apoptosis that can act: (1) at a pre-mitochondrial stage by inhibiting stress inducing signaling; (2) at the mitochondrial stage, by preventing mitochondrial membrane permeabilization, and (3) at the post-mitochondrial level by inhibiting caspase activation and DNA fragmentation (fig. 1). This essential role of HSP70 in apoptosis has been confirmed by gene ablation studies.

\section{HSP90}

HSP90 is also implied in the balance of apoptosis versus cell survival after induction of stress (fig. 1). Although most studies do not differentiate between the 2 isoforms of this protein, HSP90 $\alpha$ and HSP90 $\beta$, it is believed that they have many overlapping functions. As an ATP-dependant chaperone, HSP90 acts mostly as a homodimer that forms a hydrophobic pocket in order to interact with client proteins. HSP90 associates with numerous signaling proteins including ligand-dependent transcription factors such as steroid receptors, or ligand-independent transcription factors such as signal-transducing kinases. HSP90 can also promote the conformational maturation of proteins implied in cell cycle regulation. It is still not known if the different client proteins have a different affinity for one or other HSP90 isoform.

HSP90 regulates the activity and stability of many transcription factors and kinases implicated in apoptosis, such as NF- $\mathrm{B}$, p53, Akt, Raf-1 and JNK [17]. HSP90 can affect NF- $\kappa B$ survival activity via the IKK complex. This complex is composed of 2 catalytic and 1 regulatory subunit, HSP90 and Cdc37 [18, 19]. HSP90 has also been implicated in apoptosis induced by p53. It has been demonstrated that HSP90 associates to mutated p53 and stabilizes the protein [20]. HSP90 interacts with and stabilizes phosphorylated Akt. In turn, phosphorylated Akt can phosphorylate the pro-apoptotic $\mathrm{Bcl}-2$ family protein BAD and the caspase-9 [21], leading to their inactivation and to cell survival. Akt has also been shown to phosphorylate the I- $\kappa \mathrm{B}$ kinase, which results in promotion of NF- $\kappa \mathrm{B}$-mediated cell survival.

Another pathway of cell survival in which HSP90 can be involved is the steroid nuclear receptors pathway. In the absence of stimulation, the interactions of HSP70, HSP40 and HSP90 lead to stabilization of the complex in order to prevent its activity. HSP90 is implied in the maturation, intracellular transport and regulation of these receptors. An ATP-dependant conformational change occurs when the specific ligand interacts with its receptor leading to translocation of transcription factors to the nucleus and expression of target genes.

A key regulator in apoptosis induced by TRAIL is FLIP(S). It has been shown in glioma cells that HSP90 $\alpha$ associates with $\operatorname{FLIP}(S)$ in a manner dependent on the ATP-binding N-terminal domain of the chaperone. Following TRAIL exposure, HSP $90 \alpha$ and its client protein FLIP(S) are recruited to the DISC. HSP90 $\alpha$ depletion blocks the recruitment of FLIP(S) to the DISC and thereby sensitizes resistant glioma cells to TRAIL-induced apoptosis [22]. HSP90 has also been shown to interact with and stabilize the receptor interacting protein (RIP). Upon ligation of TNFR-1, RIP-1 is recruited to the receptor and promotes the activation of NF- $\mathrm{KB}$ and JNK. Degradation of RIP-1 in the absence of HSP90 precludes activation of NF- $\kappa$ B mediated by TNF $\alpha$ and sensitizes cells to apoptosis [23].

HSP90 has also been shown to directly block apoptosis at a post-mitochondrial level. HSP90 associates to APAF1 leading to an inhibition of caspase activation [24]. Some reports describe the formation of Bcl-2 and HSP90 $\beta$ complex preventing the release of cy tochrome $c$ from mitochondria and activation of caspase 3 in mast cells [25]. This effect was confirmed in monocytes/macrophages and dendritic cells treated with an unmethylated $\mathrm{CpG}$ motif of bacterial DNA. The authors show that HSP90 $\beta$, but not $\mathrm{HSP} 90 \alpha$, is able to associate to Bcl-2. Inhibition of HSP90 with radicicol inhibits this association [26]. In tumor cells, HSP90 is present in the mitochondria associated to its related molecule TRAP-1. It has been shown that this mitochondria-located HSP90 regulates mitochondrial membrane permeabilization and cytochrome $c$ release. The inhibition of mitochondrial HSP90 provokes a depolarization of the mitochondrial membrane and a dose-dependent release of cytochrome $c$. This might have important consequences in cancer therapy since HSP90 chaperone is only localized in tumor cells' mitochondria but not in mitochondria isolated from normal tissues [27]. 


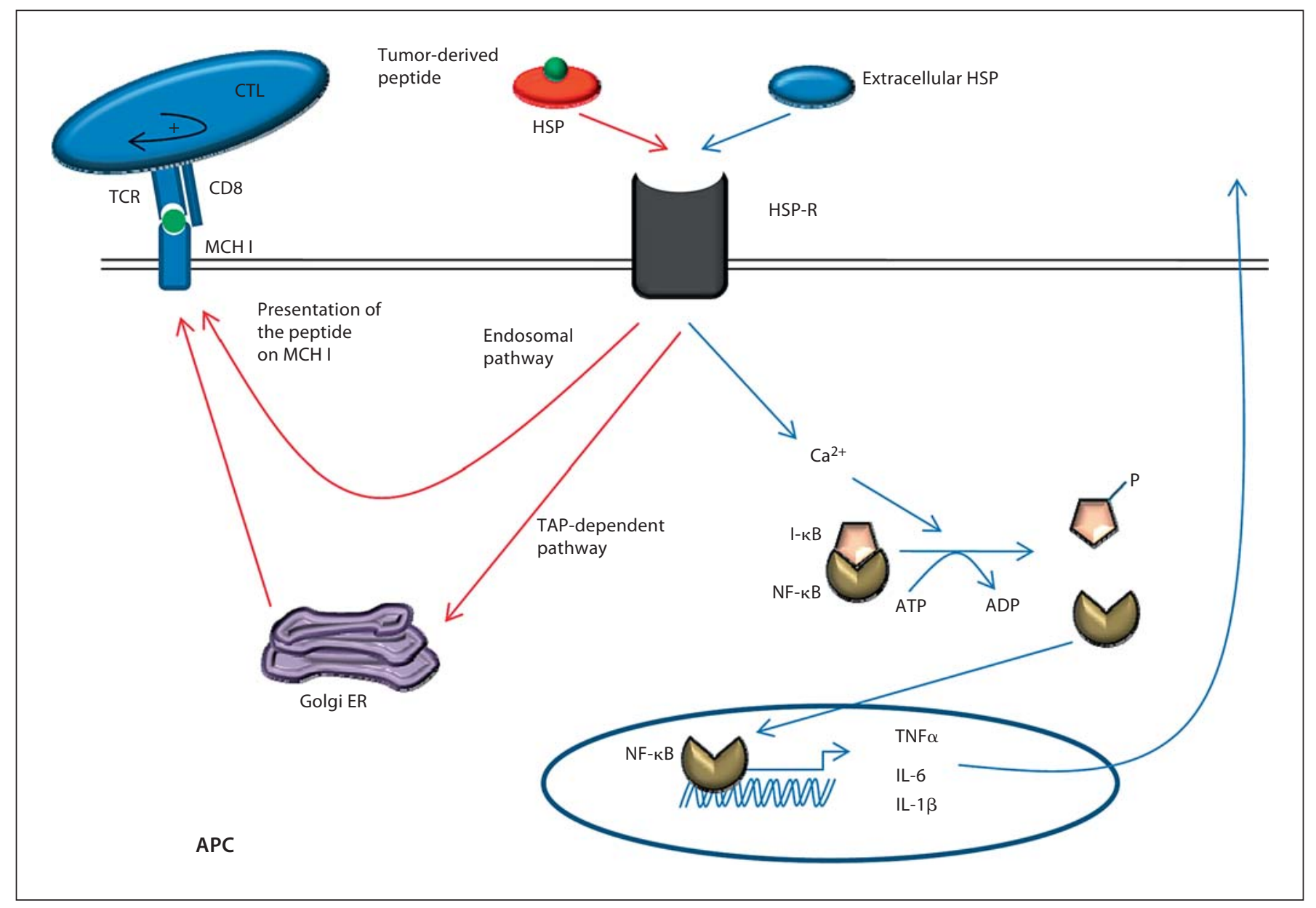

Fig. 2. Chaperokine versus tumor-antigen carrier functions of HSP. (1) Recombinant HSP70 engages signaling receptors (e.g. CD40 or TLR2/4 with the coreceptor CD14) triggering NF-кB activation leading to the release of pro-inflammatory innate immune system molecules. (2) HSPs can also chaperone antigenic peptides derived from tumor cells and internalize them by endocytosis via several putative receptors (DC40, TLR2/4 and/or CD14). After peptides are taken up and processed, they are presented to the APC via MCH class I molecules which results in $\mathrm{CD}^{+} \mathrm{T}$ cell activation.
In conclusion, the role of HSP90 in cell survival/apoptosis seems related to the proteins chaperoned by HSP90. Depending on the cancer cell model, the relevance of a given HSP90 client protein might be different.

\section{Inhibition of HSPs in Cancer Therapy}

Clinical studies often associated HSP70 or HSP90 with a poor prognosis. Increased expression of HSP70 has been reported in many tumors, such as breast, endometrial or gastric cancer, where it has been associated with metastasis, poor prognosis and resistance to chemotherapy or radiation therapy. Concerning HSP90, an overexpression of the protein has been reported in tumors such as breast, lung and hematopoietic malignancies [28].
Constitutively high expression of HSP70 is essential for the survival of most cancer cells. Inhibiting HSP70 seems to be a good strategy to combine with chemotherapy. HSP70 antisense constructs have chemosensitizing properties and may even kill cancer cell lines (in the context of adenoviral infection) in the absence of additional stimuli [29]. Our group has demonstrated that rationally engineered decoy targets of HSP70 derived from AIF can sensitize cancer cells to apoptosis induction by neutralizing HSP70 function. These AIF-derived peptides all carry the AIF region from aa 150 to aa 228, previously defined as required for HSP70 binding [29]. These inhibitors, called ADD70 (for AIF-derived decoy for HSP70), bind to HSP70 but lack an apoptotic function. In vivo ex- 
periments, in a syngeneic rat colon cancer cell model and in a mouse model of melanoma (B16F10), showed that ADD70 decreased the size of the tumors for the rats and provoked an important delay in the growth of the mice tumors. In addition, ADD70 sensitizes both the rat colon cancer cells and mouse melanoma cells to the chemotherapeutic agent cisplatin. This ADD70 anti-tumorigenic effect was only observed in syngeneic animals but not in immunodeficient animals. We have demonstrated that ADD70 anti-tumorigenic effects are associated with an increase in tumor-infiltrating cytotoxic $\mathrm{CD}^{+}{ }^{+} \mathrm{T}$ cells [30]. More recently, we have selected combinational peptide aptamers from 2 peptide aptamer libraries, consisting of an Escherichia coli thioredoxin scaffold displaying variable peptide loops of 8 or 13 amino acids. The screening was based on the ability of the aptamers to interact with HSP70 in a yeast 2-hybrid assay. Two among these peptide aptamers (A8 and A17) increased the sensitivity to apoptosis induction by anticancer drugs and, in vivo, have a strong anti-tumor effect. A8 and A17, which interacted with the ATP-binding and the peptide binding domains of HSP70, respectively, both inhibited HSP70 chaperone activity, yet did not affect that of HSC70 or HSP90 (patented in 2008).

Concerning chemical molecules specific for HSP70, recently Leu et al. [31] described a small molecule inhibitor that interacts with the C-terminus of HSP70 called 2-phenylethynesulfonamide (PES). PES interaction with HSP70 chaperone activity leads to aggregation of misfolded proteins and destabilization of lysosome membranes, and thus to induction of an autophagic cell death [31]. However, other reports indicate that PES induces a clear apoptotic, caspase-dependent, cell death [32]. The ability of PES to induce an apoptotic or autophagic cell death could be cell-type dependent.

In contrast to HSP70, many inhibitors of HSP90 are available that can be clinically tested. The rationale for their use in cancer therapy is that many HSP90 client proteins are involved in oncogenesis. Therefore, pharmacological inhibition of HSP90 results in the oncogenic protein proteasomal degradation, inhibition of tumor growth through $\mathrm{G}_{1}$ arrest and activation of apoptosis. Due to the specificity of the ATP domain of HSP90, different inhibitors targeting the ATP pocket have been developed, such as 17-allylamino-17-demethoxygeldanamycine (17-AAG) or its more soluble derivative 17-DMAG, both derived from geldanamycin, a natural molecule. The 2 drugs are currently undergoing different phase I and II clinical trials for anticancer activity, either alone or in combination with other anticancer agents. For example, HSP90 inhib- itors can be used in combination with histone deacetylase (HDAC) inhibitors since 17-AAG treatment have been shown to render acute myeloid leukemia cells sensitive to HDAC inhibitors [33]. A first phase I study with 17DMAG in patients with acute myeloid leukemia has just been finished [34]. Another class of HSP90 inhibitors that have been tested are purine-scaffold inhibitors, which mimic the conformation of ADP in the HSP90 pocket, such as CNF2024, PU-H71 and PU-DZ8 [28]. The molecular basis for the selective anti-tumoral activity of the HSP90 inhibitors seems to be the conformation of the HSP90 complex. HSP90 isolated from tumor cells has a binding affinity for the inhibitors between 20 and 200 times higher than does HSP90 isolated from normal cells. This might be due to the fact that tumor cells, as compared to their normal counterparts, might exhibit a stressed phenotype, with an enhanced dependency on the cytoprotective action of HSP90.

However, all HSP90 inhibitors have been demonstrated, both in vitro and in vivo, to strongly induce HSP70 expression [30], a highly protective protein that may strongly reduce the cell death effect provoked by HSP90 inhibition. Therefore, combining both an inhibitor of HSP90 and an inhibitor of HSP70 would be a very interesting approach in cancer therapy.

In conclusion, all these findings demonstrate why there is interest in developing novel therapeutic drugs targeting HSP70 and HSP90 to improve patient outcome in many different cancers.

\section{Extracellular HSPs}

\section{HSPs in the Extracellular Space}

The main secreted or membrane-bound HSPs are HSP70, HSP90 and gp96. These external HSPs can interact with the immune system during stress conditions (e.g. inflammation, bacterial or viral infections). Appearance of pathogen-derived HSPs in the extracellular space signals a local infection whereas appearance of mammalian HSPs is usually the result of an intracellular trauma.

How can HSPs which do not have a consensual secretory signal join the extracellular space? Different secretion mechanisms are possible [35]. Since transport of other proteins across lipid membranes is one of the tasks of HSPs, it is assumed that cytosolic HSPs could be transported to the plasma membrane in concert with other proteins possessing transmembrane domains that fulfill shuttle functions. However, the molecular nature of these associated proteins has not yet been identified. Calder- 
wood's team reported that the presence of cytosolic HSPs in the extracellular medium resulted from necrosis after cell injury. However, since undamaged cells also released HSP70, Hunter-Lavin et al. [36] reported an active nonclassical secretory pathway that could not be affected by inhibitors that antagonize transport through the ERGolgi system. Other authors have reported that after stress, HSP70 and HSC70 display an interaction with phosphatidylserine moieties on membranes, followed by rapid incorporation into the lipid bilayer. Finally, De Maio's group demonstrated that once HSP70 and HSC70 are anchored in the membrane via their $\mathrm{C}$-terminus sequences, these proteins could then be released via exosome formations that activate macrophages [37].

gp96, the ER counterpart of HSP90, plays an important role in secreted protein traffic. This protein has a KDEL sequence that allows it to be retained in the ER. It can be hypothesized that for gp96 to join the extracellular space, this sequence has to be masked or even cleaved by cathepsin-P, as recently suggested by Hassanein et al. [38].

HSPs can interact in different ways with the innate immune system (fig. 2). First, they can act as cytokines and induce activation of antigen-presenting cells (APC) assessed by secretion of pro-inflammatory cytokines or maturation of dendritic cells (DC). Second, due to their chaperone function, HSPs can act as carriers that will deliver antigenic peptides to APC. Peptides will enter the cross presentation pathway to be presented to the immune system via CMH class 1 . HSPs may therefore provide a link between innate and adaptive immune systems.

\section{HSPs and Cytokine Functions}

Even if it remains unclear whether HSPs are released as free soluble proteins or in detergent-soluble membrane vesicles, members of the HSP70 and HSP90 groups, in absence of immunogenic peptides, may serve as 'danger signals' to the host's immune system. To induce an immune response, HSPs must bind to specific receptors on the surface of specialized cells. The binding will stimulate a cascade of signals that will eventually induce the production and release of immune molecules. Around the year 2000 the term 'chaperokine' appeared, which better describe the unique function of HSPs as both chaperone and cytokine. Since then, a lot of studies have attested the roles of HSPs in the immune system. Calderwood's team showed that members of the HSP70 family have the capacity to stimulate TLR-2/TLR-4 and the CD14-associated pathway on human monocytes, leading to initiation of the NF- $\kappa \mathrm{B}$ and IRF signaling pathways. This 'chaperokine' function resulted in a stimulation of the innate immune system via the secretion of pro-inflammatory cytokines including IL-1 $\beta$, IL- 6 and TNF $\alpha$ $[39,40]$. Accordingly, membrane-bound HSP70 has been shown to activate macrophages [37]. A recent study showed that during monocyte to DC transition, HSP70 was upregulated, leading to an increase in intracellular, membrane-bound and secreted HSP70. Heat stress leads only to an increase in intracellular HSP70 contrary to specific pro-inflammatory cytokine treatment that also promotes extracellular HSP70 accumulation. The authors suggested that an extracellular HSP70 could be recognized by the HSP receptor CD40 pathway that may be involved in an autocrine-positive DC growth response through upregulation of anti-apoptotic molecules [41]. In contrast, a study performed on $\mathrm{CD} 40^{-/-}$mice proved that the HSP70 cytokine effect was CD40-independent [42]. These contradictory publications underline the fact that the established list of HSP receptors is very controversial [43].

HSP70 are also found to be expressed on the plasma membrane of malignantly transformed cells or tumorderived exosomes. Many reports focus on the possible immunoadjuvant effect of exosome HSPs, which enhance the maturation of dendritic and NK cells [44, 45], thus leading to immune-mediated protection. This hypothesis was challenged by reports showing that HSPs can also downregulate an immune response in some autoimmune models such as rheumatoid arthritis in rats and diabetes in mice. The mechanism proposed for the immunoregulatory function of HSPs involved the generation of IL-10-producing immunosuppressive T cells. In this regard, it is noteworthy that extracellular HSP70 could also render APC resistant to adjuvant-induced maturation. In a recent study, we demonstrated that HSP70 expression in tumor-derived exosomes is detrimental for the antitumor response. We showed both in mice and humans that HSP70 expressed on exosome surface triggers Stat 3 activation in myeloid-derived suppressor cells (MDSCs) in a TLR2/MyD88-dependent manner through an autocrine production of IL-6 [46]. HSP70 cytokine properties are well described and related to its capacity to bind to TLR4/CD14 complex or TLR2. Conflicting reports suggest that the adjuvant Toll-dependent effects of HSPs are due to LPS or lipopeptide contamination [47]. In our study, we performed for the first time physical measurement of the interaction between HSP70 and TLR2 by surface plasmon resonance, thus definitively demonstrating the potent capacity of HSP70 to interact directly with TLR2. 


\section{HSPs and Antigen Presentation}

Cancer cells can be considered as permanently stressed cells that therefore express a highly abnormal level of HSPs. Due to HSP chaperone activity, HSP-tumoral peptides can be released in the extracellular space. HSPs can interact with the APC through different putative receptors. These include: (1) the low-density lipoprotein receptor-related protein CD91; (2) the TNF receptor family member, CD40; (3) members of the scavenger receptor family such as Lox-1 [43]. After endocytosis, the complexes are degraded and tumoral peptide could be crosspresented to CD8 T cells through MHC class I molecules. Interactions with the adaptive system result in $\mathrm{CD} 8^{+} \mathrm{T}$ cell response and tumor cell eradication. This discovery opened HSP-based cancer vaccines research.

HSP-based vaccines work across tumor types, bypassing the need for the identification of the single immunogenic peptide, and thus emerging as a class of tumor- and patient-specific vaccines. One of the most promising tumor-derived HSP-peptide complexes (HSPPCs) tested as a vaccine is the HSPPC-96-based vaccine Vitespen ${ }^{\circledR}$ (formerly Oncophage $\left.{ }^{\circledR}\right)$. This is a personalized vaccine developed by Antigenics that consists of an extract containing gp96-peptide complexes prepared from an individual patient's excised tumor. It confirmed its activity in different malignancies (e.g. gastric cancer, colorectal cancer, pancreatic cancer, non-Hodgkin's lymphoma and chronic myelogenous leukemia), and showed promising results in phase III clinical trials in melanoma and kidney cancer $[48,49]$. HSP-based vaccines are emerging as a novel therapeutic approach with a suggestive role in cancer therapy. A scientific issue of the approach might be to elucidate the nature of HSP-chaperoned peptides since purification of the HSP-peptide complexes from patient-derived tumors limits the amount of vaccine it is possible to produce.

\section{Concluding Remarks: Is HSP Inhibition in Cancer Therapy a Good Strategy?}

While intracellular HSP90 and, more recently, HSP70 have become very exciting anticancer molecular targets, a relatively small number of studies have suggested that a pool of the chaperones are located on the cell surface, facing the extracellular space, and that this fraction of HSPs may have unique and unexpected properties. The reported environmental cues that trigger cells to secrete HSPs include ROS, heat, hypoxia, gamma-irradiation and injury-released growth factors. Membrane-bound HSPs activate macrophage $\mathrm{APC}$ leading to $\mathrm{CD} 8^{+} \mathrm{T}$ cell activation.
Concerning extracellular HSPs, they can either act as chaperones for tumor peptide antigens thereby eliciting an immune anti-tumor response or act like 'chaperokines'. The latter is a more controversial function that, in some cases, has been attributed to endotoxin or LPS contamination. Because HSPs tightly bind to circulating LPS, they might have a function in LPS transport and in enhancing the immune-stimulatory effect of LPS. Further studies are necessary to elucidate this in vivo effect of external HSPs.

The dual role of HSPs depending on their intracellular or extracellular location may be a paradox in cancer therapy. HSPs are over-expressed in cancer cells leading to chemotherapy resistance whereas extracellular or membrane-bound HSPs seem to participate in cancer cell destruction by the immune system. However, intracellular HSPs can also affect the immune response by affecting either immune cell survival or differentiation. For instance, HSP60 and HSP70 seem to be involved in neutrophil apoptosis in response to bacteria, and phagocytosis of such cells leads to macrophage stimulation [50]. During differentiation of monocytes to DC there is an induction of intracellular HSP70. The inhibition of this heat shock response by triptolide or KNK-437 seems to abrogate DC differentiation, suggesting that the accumulation of intracellular HSP70 is important for this differentiation process [41]. Moreover, not all extracellular effects of HSPs are anti-tumoral. Eustace et al. [51] showed that the HSP90 $\alpha$ isoform, but not HSP90 $\beta$, is expressed extracellularly where it interacts with the matrix metalloproteinase 2 (MMP2). Inhibition of extracellular HSP90 $\alpha$ decreases both MMP2 activity and invasiveness. This role for extracellular HSP90 $\alpha$ in MMP2 activation indicates that cell-impermeable anti-HSP90 drugs might decrease invasiveness without the concerns inherent in inhibiting intracellular HSP90 [51]. All these data explain why many laboratories are now working to develop new inhibitors of HSP90 and HSP70, both those able and those unable to penetrate the cells.

In a theoretically ideal anticancer therapeutic approach, both therapies based on intracellular and extracellular HSP properties could be tried successively. First would be the inhibitors of HSPs in association with a classical chemotherapy to increase the sensitivity of cancer cells to the cytotoxic drug. Second would come the HSPbased therapy to boost the immune system and thereby avoid the apparition of metastasis. In conclusion, the dual function of HSPs, depending on their location, makes them interesting molecules in cancer therapy. 


\section{References}

$>1$ Guo F, Sigua C, Bali P, George P, Fiskus W, 12 Ribeil JA, Zermati Y, Vandekerckhove J, Scuto A, Annavarapu S, Mouttaki A, Sondarva G, Wei S, Wu J, Djeu J, Bhalla K: Mechanistic role of heat shock protein 70 in bcrabl-mediated resistance to apoptosis in human acute leukemia cells. Blood 2005;105: 1246-1255.

-2 Pang Q, Christianson TA, Keeble W, Koretsky T, Bagby GC: The anti-apoptotic function of HSP70 in the interferon-inducible double-stranded RNA-dependent protein kinase-mediated death signaling pathway requires the Fanconi anemia protein, FANCC. J Biol Chem 2002;277:4963849643.

$\checkmark 3$ Gao T, Newton AC: The turn motif is a phosphorylation switch that regulates the binding of HSP70 to protein kinase C. J Biol Chem 2002;277:31585-31592.

4 Gabai VL, Mabuchi K, Mosser DD, Sherman MY: HSP72 and stress kinase C-jun N-terminal kinase regulate the bid-dependent pathway in tumor necrosis factor-induced apoptosis. Mol Cell Biol 2002;22:3415-3424.

5 Stankiewicz AR, Livingstone AM, Mohseni N, Mosser DD: Regulation of heat-induced apoptosis by MCL-1 degradation and its inhibition by HSP70. Cell Death Differ 2009; 16:638-647.

$\checkmark 6$ Park HS, Lee JS, Huh SH, Seo JS, Choi EJ: HSP72 functions as a natural inhibitory protein of C-jun N-terminal kinase. Embo J 2001;20:446-456.

$>7$ Park HS, Cho SG, Kim CK, Hwang HS, Noh KT, Kim MS, Huh SH, Kim MJ, Ryoo K, Kim EK, Kang WJ, Lee JS, Seo JS, Ko YG, Kim S, Choi EJ: Heat shock protein HSP72 is a negative regulator of apoptosis signal-regulating kinase 1. Mol Cell Biol 2002;22:7721-7730.

$>8$ Lachapelle G, Radicioni SM, Stankiewicz AR, Mosser DD: Acute acidification or amiloride treatment suppresses the ability of HSP70 to inhibit heat-induced apoptosis. Apoptosis 2007;12:1479-1488.

$>9$ Lee KH, Lee CT, Kim YW, Han SK, Shim YS, Yoo CG: Preheating accelerates mitogen-activated protein (MAP) kinase inactivation post-heat shock via a heat shock protein 70-mediated increase in phosphorylated map kinase phosphatase-1. J Biol Chem 2005;280:13179-13186.

10 Beere HM, Wolf BB, Cain K, Mosser DD, Mahboubi A, Kuwana T, Tailor P, Morimoto RI, Cohen GM, Green DR: Heat-shock protein 70 inhibits apoptosis by preventing recruitment of procaspase- 9 to the APAF-1 apoptosome. Nat Cell Biol 2000;2:469-475.

$>11$ Sakahira H, Nagata S: Co-translational folding of caspase-activated DNase with HSP70, HSP40, and inhibitor of caspase-activated DNase. J Biol Chem 2002;277:3364-3370. Cathelin S, Kersual J, Dussiot M, Coulon S, Moura IC, Zeuner A, Kirkegaard-Sorensen T, Varet B, Solary E, Garrido C, Hermine O: HSP70 regulates erythropoiesis by preventing caspase-3-mediated cleavage of GATA-1. Nature 2007;445:102-105.

13 Ravagnan L, Gurbuxani S, Susin SA, Maisse C, Daugas E, Zamzami N, Mak T, Jaattela M, Penninger JM, Garrido C, Kroemer G: Heatshock protein 70 antagonizes apoptosis-inducing factor. Nat Cell Biol 2001;3:839-843.

14 Park MA, Zhang G, Norris J, Hylemon PB, Fisher PB, Grant S, Dent P: Regulation of autophagy by ceramide-CD95-perk signaling. Autophagy 2008;4:929-931.

15 Nylandsted J, Gyrd-Hansen M, Danielewicz A, Fehrenbacher N, Lademann U, HoyerHansen M, Weber E, Multhoff G, Rohde M, Jaattela M: Heat shock protein 70 promotes cell survival by inhibiting lysosomal membrane permeabilization. J Exp Med 2004; 200:425-435.

16 Kirkegaard T, Roth AG, Petersen NH, Mahalka AK, Olsen OD, Moilanen I, Zylicz A, Knudsen J, Sandhoff K, Arenz C, Kinnunen PK, Nylandsted J, Jaattela M: HSP70 stabilizes lysosomes and reverts Niemann-Pick disease-associated lysosomal pathology. Nature;463:549-553.

17 Westerheide SD, Kawahara TL, Orton K, Morimoto RI: Triptolide, an inhibitor of the human heat shock response that enhances stress-induced cell death. J Biol Chem 2006; 281:9616-9622.

18 Hinz M, Broemer M, Arslan SC, Otto A, Mueller EC, Dettmer R, Scheidereit C: Signal responsiveness of ikappab kinases is determined by CDC37-assisted transient interaction with HSP90. J Biol Chem 2007;282: 32311-32319.

19 Salminen A, Paimela T, Suuronen T, Kaarniranta $\mathrm{K}$ : Innate immunity meets with cellular stress at the IKK complex: regulation of the IKK complex by HSP70 and hsp90. Immunol Lett 2008;117:9-15.

20 Lin K, Rockliffe N, Johnson GG, Sherrington PD, Pettitt AR: HSP90 inhibition has opposing effects on wild-type and mutant p53 and induces p21 expression and cytotoxicity irrespective of $\mathrm{p53/ATM}$ status in chronic lymphocytic leukaemia cells. Oncogene 2008;27: 2445-2455.

21 Cardone MH, Roy N, Stennicke HR, Salvesen GS, Franke TF, Stanbridge E, Frisch S, Reed JC: Regulation of cell death protease caspase- 9 by phosphorylation. Science 1998; 282:1318-1321.

22 Panner A, Murray JC, Berger MS, Pieper RO: Heat shock protein 90alpha recruits flips to the death-inducing signaling complex and contributes to trail resistance in human glioma. Cancer Res 2007;67:9482-9489.
23 Lewis J, Devin A, Miller A, Lin Y, Rodriguez Y, Neckers L, Liu ZG: Disruption of HSP90 function results in degradation of the death domain kinase, receptor-interacting protein (RIP), and blockage of tumor necrosis factorinduced nuclear factor-kappaB activation. J Biol Chem 2000;275:10519-10526.

24 Pandey P, Saleh A, Nakazawa A, Kumar S, Srinivasula SM, Kumar V, Weichselbaum R, Nalin C, Alnemri ES, Kufe D, Kharbanda S: Negative regulation of cytochrome $c$-mediated oligomerization of APAF-1 and activation of procaspase- 9 by heat shock protein 90. Embo J 2000;19:4310-4322.

25 Cohen-Saidon C, Carmi I, Keren A, Razin E: Antiapoptotic function of Bcl-2 in mast cells is dependent on its association with heat shock protein 90beta. Blood 2006;107:14131420 .

26 Kuo CC, Liang SM, Liang CM: CpG-B oligodeoxynucleotide promotes cell survival via up-regulation of HSP70 to increase Bcl-xL and to decrease apoptosis-inducing factor translocation. J Biol Chem 2006;281:3820038207.

27 Kang BH, Plescia J, Dohi T, Rosa J, Doxsey SJ, Altieri DC: Regulation of tumor cell mitochondrial homeostasis by an organelle-specific HSP90 chaperone network. Cell 2007; 131:257-270.

28 Didelot C, Lanneau D, Brunet M, Joly AL, De Thonel A, Chiosis G, Garrido C: Anti-cancer therapeutic approaches based on intracellular and extracellular heat shock proteins. Curr Med Chem 2007; 14:2839-2847.

29 Gurbuxani S, Schmitt E, Cande C, Parcellier A, Hammann A, Daugas E, Kouranti I, Spahr C, Pance A, Kroemer G, Garrido C: Heat shock protein 70 binding inhibits the nuclear import of apoptosis-inducing factor. Oncogene 2003;22:6669-6678.

30 Schmitt E, Maingret L, Puig PE, Rerole AL, Ghiringhelli F, Hammann A, Solary E, Kroemer G, Garrido C: Heat shock protein 70 neutralization exerts potent antitumor effects in animal models of colon cancer and melanoma. Cancer Res 2006;66:4191-4197.

31 Leu JI, Pimkina J, Frank A, Murphy ME, George DL: A small molecule inhibitor of inducible heat shock protein 70. Mol Cell 2009; 36:15-27.

>32 Steele AJ, Prentice AG, Hoffbrand AV, Yogashangary BC, Hart SM, Lowdell MW, Samuel ER, North JM, Nacheva EP, Chanalaris A, Kottaridis P, Cwynarski K, Wickremasinghe RG: 2-phenylacetylenesulfonamide (pas) induces p53-independent apoptotic killing of b-chronic lymphocytic leukemia (CLL) cells. Blood 2009;114:12171225. 
- 33 Fiskus W, Rao R, Fernandez P, Herger B, Yang Y, Chen J, Kolhe R, Mandawat A, Wang Y, Joshi R, Eaton K, Lee P, Atadja P, Peiper S, Bhalla K: Molecular and biologic characterization and drug sensitivity of pan-histone deacetylase inhibitor-resistant acute myeloid leukemia cells. Blood 2008;112:28962905.

34 Lancet JE, Gojo I, Burton M, Quinn M, Tighe SM, Kersey K, Zhong Z, Albitar MX, Bhalla K, Hannah AL, Baer MR: Phase I study of the heat shock protein 90 inhibitor alvespimycin (KOS-1022, 17-DMAG) administered intravenously twice weekly to patients with acute myeloid leukemia. Leukemia 2010, E-pub ahead of print.

- 35 Mambula SS, Stevenson MA, Ogawa K, Calderwood SK: Mechanisms for HSP70 secretion: crossing membranes without a leader. Methods 2007;43:168-175.

- 36 Hunter-Lavin C, Davies EL, Bacelar MM, Marshall MJ, Andrew SM, Williams JH: HSP70 release from peripheral blood mononuclear cells. Biochem Biophys Res Commun 2004;324:511-517.

-37 Vega VL, Rodriguez-Silva M, Frey T, Gehrmann M, Diaz JC, Steinem C, Multhoff G, Arispe N, De Maio A: HSP70 translocates into the plasma membrane after stress and is released into the extracellular environment in a membrane-associated form that activates macrophages. J Immunol 2008; 180: 4299-4307.

- 38 Hassanein M, Bojja AS, Glazewski L, Lu G, Mason RW: Protein processing by the placental protease, cathepsin P. Mol Hum Reprod 2009; 15:433-442.

39 Asea A, Kraeft SK, Kurt-Jones EA, Stevenson MA, Chen LB, Finberg RW, Koo GC, Calderwood SK: HSP70 stimulates cytokine production through a CD14-dependant pathway, demonstrating its dual role as a chaperone and cytokine. Nat Med 2000;6: 435-442.
40 Asea A, Rehli M, Kabingu E, Boch JA, Bare O, Auron PE, Stevenson MA, Calderwood SK: Novel signal transduction pathway utilized by extracellular hsp70: Role of toll-like receptor (TLR) 2 and TLR4. J Biol Chem 2002;277:15028-15034.

41 Martin CA, Kurkowski DL, Valentino AM, Santiago-Schwarz F: Increased intracellular, cell surface, and secreted inducible heat shock protein 70 responses are triggered during the monocyte to dendritic cell (DC) transition by cytokines independently of heat stress and infection and may positively regulate DC growth. J Immunol 2009; 183: 388-399.

42 Binder RJ: CD40-independent engagement of mammalian HSP70 by antigen-presenting cells. J Immunol 2009;182:6844-6850.

43 Calderwood SK, Mambula SS, Gray PJ Jr: Extracellular heat shock proteins in cell signaling and immunity. Ann NY Acad Sci 2007; 1113:28-39.

44 Multhoff G: Activation of natural killer cells by heat shock protein 70. Int J Hyperthermia 2002;18:576-585.

45 Elsner L, Muppala V, Gehrmann M, Lozano J, Malzahn D, Bickeboller H, Brunner E, Zientkowska M, Herrmann T, Walter L, Alves F, Multhoff G, Dressel R: The heat shock protein HSP70 promotes mouse NK cell activity against tumors that express inducible NKG2D ligands. J Immunol 2007; 179:5523-5533.

46 Chalmin F, Ladoire S, Mignot G, Vincent J, Bruchard M, Remy-Martin JP, Boireau W, Rouleau A, Simon B, Lanneau D, De Thonel A, Multhoff G, Hamman A, Martin F, Chauffert B, Solary E, Zitvogel L, Garrido C, Ryffel B, Borg C, Apetoh L, Rébé C, Ghiringhelli F: Membrane-associated Hsp72 from tumor-derived exosomes mediates STAT3dependent immunosuppressive function of mouse and human myeloid-derived suppressor cells. J Clin Invest 2010;120:457-471.
7 Tsan MF, Gao B: Heat shock proteins and immune system. J Leukoc Biol 2009;85:905910.

48 Testori A, Richards J, Whitman E, Mann GB, Lutzky J, Camacho L, Parmiani G, Tosti G, Kirkwood JM, Hoos A, Yuh L, Gupta R, Srivastava PK: Phase III comparison of vitespen, an autologous tumor-derived heat shock protein gp96 peptide complex vaccine, with physician's choice of treatment for stage IV melanoma: the c-100-21 study group. J Clin Oncol 2008;26:955-962.

49 Wood C, Srivastava P, Bukowski R, Lacombe L, Gorelov AI, Gorelov S, Mulders P, Zielinski $\mathrm{H}$, Hoos $\mathrm{A}$, Teofilovici $\mathrm{F}$, Isakov $\mathrm{L}$, Flanigan R, Figlin R, Gupta R, Escudier B: An adjuvant autologous therapeutic vaccine (HSPPC-96; vitespen) versus observation alone for patients at high risk of recurrence after nephrectomy for renal cell carcinoma: a multicentre, open-label, randomised phase III trial. Lancet 2008;372:145-154.

50 Zheng L, He M, Long M, Blomgran R, Stendahl O: Pathogen-induced apoptotic neutrophils express heat shock proteins and elicit activation of human macrophages. J Immunol 2004;173:6319-6326.

51 Eustace BK, Sakurai T, Stewart JK, Yimlamai D, Unger C, Zehetmeier C, Lain B, Torella C, Henning SW, Beste G, Scroggins BT, Neckers L, Ilag LL, Jay DG: Functional proteomic screens reveal an essential extracellular role for HSP90 alpha in cancer cell invasiveness. Nat Cell Biol 2004;6:507-514. 